\title{
Experimental tests of the elementary mechanism responsible for creep deformation in nanocrystalline gold
}

\author{
N. Yagi, A. Rikukawa, H. Mizubayashi, and H. Tanimoto \\ Institute of Materials Science, University of Tsukuba, Tsukuba 305-8573, Japan \\ (Received 29 May 2006; revised manuscript received 29 August 2006; published 20 October 2006)
}

\begin{abstract}
Creep deformation tests at room temperature were carried out on nanocrystalline $(n-)$ Au prepared by the gas-deposition method, where the mean primary grain size was $\sim 20 \mathrm{~nm}$ but most of the primary grains formed clusters with a mean size of $\sim 50 \mathrm{~nm}$ (called secondary grains after this). X-ray (111) reflection was predominant in the $n$-Au specimens in the as-deposited state and the mean grain size estimated from this reflection had good agreement with that of the secondary grains. The secondary grains came out onto the specimen surfaces and sank into them in the in situ scanning tunneling microscope observations done during the creep tests. This indicated that secondary grains in $n$-Au can move as a whole without coalescence with neighboring grains and such secondary-grain motion cannot be explained by diffusion-mediated mechanisms. Further, a large decrease in the x-ray (111) reflection and no changes in either the mean size of the secondary grains or the x-ray diffuse scattering pattern were observed after creep deformations. These results indicate that the grain-boundary slips in $n$ - $\mathrm{Au}$ are associated with rotations of the secondary grains. The transition in heterogeneous grain-boundary slips to homogeneous grain-boundary slips with increasing stress found in virgin $n$-Au specimens was again observed in predeformed $n$-Au specimens, indicating that the modified grain-boundary regions due to grain boundary slips can be recovered after unloading, i.e., grain-boundary regions have static and modified structures.
\end{abstract}

DOI: 10.1103/PhysRevB.74.144105

\section{INTRODUCTION}

Deformation in ductile metals is governed by dislocation motion when the mean grain size $d$, is larger than a certain threshold $d_{\mathrm{c}}$, of several tens of nanometers, where the yield strength increases in proportion with $d^{-1 / 2}$ (the Hall-Petch relation). ${ }^{1,2}$ The yield strength saturates at around $d=d_{\mathrm{c}}$, then reduces with decreasing mean grain size for $d<d_{\mathrm{c}}$ (the inverse Hall-Petch relation). ${ }^{3}$ Various models have been proposed to explain the inverse Hall-Petch relation. ${ }^{4-6}$ The diffusion-mediated deformation mechanism is known to become predominant when the mean grain size is as small as the diffusion length expected for the mechanism. ${ }^{7,8}$ The strain rate $d \varepsilon / d t$, mediated by grain-boundary diffusion in a polycrystalline material was formulated by $\mathrm{Coble}^{7}$ and is given by

$$
d \varepsilon / d t=\alpha D_{\mathrm{GB}} \delta_{\mathrm{GB}} \sigma \Omega / d^{3} k_{\mathrm{B}} T,
$$

where $D_{\mathrm{GB}}$ is the grain-boundary diffusion coefficient, $\delta_{\mathrm{GB}}$ is the grain-boundary thickness, and $\Omega$ is the atomic volume. Here, $\sigma$ is the applied stress, $T$ is the temperature, $k_{\mathrm{B}}$ is the Boltzmann constant, and $\alpha$ is a proportional constant. Further, Ashby ${ }^{8}$ took the sliding of the grain boundary into account and proposed a similar equation with an increased rate. Diffusion-mediated deformation can be observed in hightemperature creep tests on conventional polycrystalline metals with a mean grain size larger than $1 \mu \mathrm{m}$. Viscous flow can play a major role in deformation at room temperature in nanocrystalline metals with a mean grain size of less than $d_{\mathrm{c}}{ }^{3}$ Creep deformation tests at room temperature were carried out on nanocrystalline gold (called $n$-Au after this) to clarify the deformation mechanism in ductile nanocrystalline metals with a mean grain size of less than $d_{\mathrm{c}}{ }^{9}$
Figure 1 plots the dependence of the steady-state creep rate (called creep rate after this) at room temperature on stress reported for $n-\mathrm{Au},{ }^{9} n-\mathrm{Cu},{ }^{10-12}$ and $n-\mathrm{Ni},{ }^{13,14}$ where the creep rates for $n$-Au specimens predicted by Ashby's and Coble's creep models are also plotted. Both models predict a linear relationship between the creep rate and stress. Al-

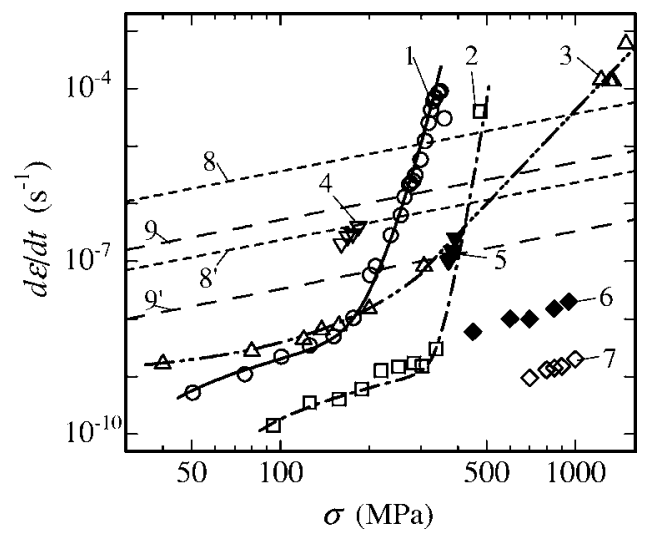

FIG. 1. Steady-state creep rate $\mathrm{d} \varepsilon / \mathrm{d} t$, vs applied stress $\sigma$. Data reported for various $n$ metals at room temperature. 1 and 2: type- $H$ $n$-Au and type- $L n$-Au with mean grain size $d$, of $\sim 20 \mathrm{~nm}$ ( $\sim 50 \mathrm{~nm}$ as secondary grains) prepared by gas-deposition (GD) method (Ref. 9). 3: $n$-Cu with $d$ of $\sim 25 \mathrm{~nm}$ prepared by GD (Ref. 10). 4: $n$-Cu with $d$ of $\sim 30 \mathrm{~nm}$ prepared by electro-deposition (ED) method (Ref. 11). 5: $n$-Cu with $d$ of $\sim 30 \mathrm{~nm}$ prepared by ED (Ref. 12). 6: $n$-Ni with $d$ of $\sim 30 \mathrm{~nm}$ prepared by ED (Ref. 13). 7: $n$-Ni with $d$ of $\sim 20 \mathrm{~nm}$ prepared by ED (Ref. 14). Dashed lines 8 and $8^{\prime}$ are respective theoretical values for $n$-Au with $d$ of $20 \mathrm{~nm}$ and $40 \mathrm{~nm}$ predicted by Ashby creep model. Dashed lines 9 and $9^{\prime}$ are respective theoretical values for $n$-Au with $d$ of $20 \mathrm{~nm}$ and $40 \mathrm{~nm}$ predicted by Coble creep model. Solid line, dotted and dashed line, and double-dotted and dashed line are provided for clarity. 
though the creep rate's magnitude depends on specimen preparation conditions, its dependences on stress observed over a wide range for $n$-Au (Ref. 9) and $n$-Cu (Ref. 10) commonly revealed a nearly linear increase followed by a steep rise with increasing stress. The creep rate observed for $n$-Au in the low stress range is much lower than that predicted by Coble's model and that observed in the high stress range is much higher than that expected with Ashby's model. The dependence of creep rate on stress observed within a narrow stress range for $n$-Cu (Refs. 11 and 12) and $n$ - Ni (Refs. 13 and 14) may reflect part of the characteristic dependence of creep rate on stress previously mentioned. Therefore, the deformation in these fcc $n$ metals with $d$ $<d_{\mathrm{c}}$ is not governed by a diffusion-mediated mechanism but by some other kind. Scanning tunneling microscope (STM) observations of $n$-Au (Ref. 9) and $n$-Cu (Ref. 10) after creep deformations revealed that a nearly linear increase in the creep rate in the low stress range was associated with an increase in the number density of localized grain-boundary slips where the length was a few hundred nanometers and the height difference was a few nanometers (heterogeneous grain-boundary slips). With increasing stress, the heterogeneous grain-boundary slips developed to homogeneous grain-boundary slips between all the grains. No grain growth in $n$-Au was observed even after the homogeneous grainboundary slips, ${ }^{9}$ although grain growth was caused by annealing at about $400 \mathrm{~K} .{ }^{15}$ This indicates that all grains stably played an important role in deformation at room temperature. Consequently, questions may arise into whether the creep rate will increase further with increasing stress, and into the behaviors of grains during deformation. Further creep tests, in situ STM observations during a tensile test, and a survey of the crystallographic change as a function of deformation were conducted on $n$-Au to address these issues.

\section{EXPERIMENTAL PROCEDURE}

Fully dense $n$-Au was prepared with the gas-deposition (GD) method, ${ }^{15,16}$ where gas-condensed ultrafine gold particles were directly deposited on a substrate within a few milliseconds using a $\mathrm{He}$ gas jet. During an operation of the GD apparatus, $99.9999 \%$ pure helium was supplied to the evaporation chamber and the gas was evacuated from the evaporation and deposition chambers to the helium circulation system with purification columns. Two types of $n$-Au specimens can be prepared as a function of the deposition rate, i.e., type- $H$ specimens above $800 \mathrm{~nm} / \mathrm{s}$ and type- $L$ specimens below $800 \mathrm{~nm} / \mathrm{s}^{15}$ It should be noted that type- $H$ and type- $L$ specimens have different properties and there is an example of the dependence of their creep rate on stress in Fig. 1. Characteristics of type- $L$ and type- $H$ specimens in the as-prepared state 9,15 will briefly be given below. Both the densities of type- $L$ and type- $H$ specimens showed good agreement with the value reported for bulk $\mathrm{Au}$ metal. The STM observations for both type- $L$ and type- $H$ specimens commonly indicated that the mean grain size of grains was about $20 \mathrm{~nm}$. The x-ray diffraction (XRD) measurements indicated that a quite strong $\langle 111\rangle$ texture was commonly observed where almost the grains aligned their $\langle 111\rangle$ - orientation normal to the substrate-side surface. For both type- $L$ and type- $H$ specimens, the mean grain size estimated from the XRD measurements was about $40 \mathrm{~nm}$ for the predominant (111) reflection and about $20 \mathrm{~nm}$ for the minor (200) and (220) reflections. On the other hand, for the orientational distribution of the grains parallel to the substrateside surface, the $\langle 110\rangle-,\langle 100\rangle$-, and $\langle 111\rangle$-orientations were observed with comparable fractions and their fractions were different between type- $L$ and type- $H$ specimens. Further, an onset temperature for the grain growth was below $400 \mathrm{~K}$ for type- $H$ specimens and above $400 \mathrm{~K}$ for type- $L$ specimens. The results of the STM observations and the XRD measurements suggest that primary grains with the mean size of $\sim 20 \mathrm{~nm}$ formed clusters (called secondary grains, after this) with the size of $\sim 40 \mathrm{~nm}$. We surmise that formation of the secondary grains took place during a flight to a substrate in a $\mathrm{He}$ gas jet, where the grain-boundaries between the primary grains in the secondary grains relaxed to low-energy-specialtypes such as small-angle grain-boundaries and the $\Sigma 3$ twin boundary. On the other hand, different properties found between type- $L$ and type- $H$ specimens indicate that a rearrangement of the secondary grains on the specimen surface took place to minimize the interfacial energy, where the rearrangement was completed for type- $L$ specimens but was not sufficient for type- $H$ specimens. The $n$-Au specimens used in the present work were type- $H$ specimens.

Ribbon-shaped specimens that were $\sim 20 \mathrm{~mm}$ long, $1 \mathrm{~mm}$ wide, and $50-500 \mu \mathrm{m}$ thick were deposited on a glass substrate cooled below room temperature, and then carefully removed from the substrate. The substrate-side surface of the $n$-Au ribbon specimen was a mirror surface. STM observations and XRD measurements were done upon the substrateside surface. The free-side surface of the mechanically-tested $n$-Au ribbon specimen was gently and carefully polished to a mirror surface with emery paper. The four edges of the polished ribbon were then cut with a thin razor to shape it into a rectangle with a length of $10-15 \mathrm{~mm}$ and a width of $\sim 0.5 \mathrm{~mm}$. The thickness of specimens used for the tensile creep tests was $20-60 \mu \mathrm{m}$ and that for the compressive creep tests was $\sim 500 \mu \mathrm{m}$. The stress applied was normal to the thickness direction in the tensile creep tests and that was parallel to the thickness direction in the compressive creep tests, respectively. In both the creep tests, a direction of the mean displacement of grains was normal to the thickness direction. The plastic strain in the compressive tests was defined as $\varepsilon_{p}=\left(t_{0}-t\right) / t_{0}$, where $t_{0}$ and $t$ are the thicknesses before and after deformation. The density of the specimen was evaluated by Archimedes' principle using high-purity ethanol. The obtained density of $19.4 \pm 0.2 \mathrm{~g} / \mathrm{cm}^{3}$ had good agreement with the $19.32 \mathrm{~g} / \mathrm{cm}^{3}$ reported for bulk Au metal.

The surface topography of the $n$-Au specimens was inspected by STM operating in the constant current mode. The in situ STM observations during the tensile creep test were conducted in combination with a homemade tensile-creep apparatus. The area observed was $\sim 1 \mathrm{~mm}$ from one end of the clamping. The elapsed time was $90 \mathrm{~s}$ for a micrograph of $600 \times 600 \mathrm{~nm}$. The expected displacement of the object during the $90 \mathrm{~s}$ was $\sim 10 \mathrm{~nm}$ at a macroscopic creep rate of $10^{-7} \mathrm{~s}^{-1}$. Although the specimen moved undesirably, the surface morphology of grains with a diameter of 20 to $50 \mathrm{~nm}$ 


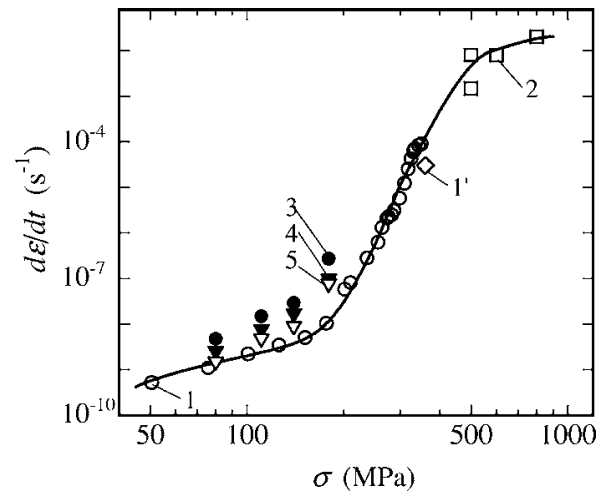

FIG. 2. Similar to Fig. 1 except steady-state creep rates observed for type- $H n$-Au are shown. Data 2 were observed in highstress compression tests. Data 3 to 5 were observed in tensile tests just after $(<1 \mathrm{ks})$, after $7 \mathrm{ks}$, and $15 \mathrm{ks}$, respectively, following predeformation by tensile test at $240 \mathrm{MPa}$ for $15 \mathrm{~s}$. Data 1 and $1^{\prime}$ were observed in respective tensile and compressive tests [see Data 1 (Ref. 9) in Fig. 1]. Solid curve is provided for clarity.

could be observed during the in situ STM observations. The overall displacement of specimens was detected with a capacitance displacement sensor. ${ }^{9}$ The mean grain size $d$, the root-mean square of local strain $\left\langle\varepsilon^{2}\right\rangle^{0.5}$, and the preferred orientation of the grains were investigated by XRD measurements by means of a $\theta-2 \theta$ scan with $\mathrm{Cu} K \alpha$ radiation, where the scattering vector was normal to the substrate-side surface of the specimen. All the STM observations and XRD measurements were carried out at room temperature.

\section{RESULTS}

The transition in the heterogeneous grain-boundary slips to the homogeneous grain-boundary slips plotted in Fig. 1 (Ref. 9) can predict a certain change in the creep rate at higher stresses. The creep rates at high stresses were measured with compression tests and the dependence on stress is plotted in Fig. 2, where a moderate increase in the creep rate was observed above $\sim 500 \mathrm{MPa}$. Tensile tests in the lowstress range for heterogeneous grain-boundary slips were conducted to find the probable dynamic grain-boundary state after various times had elapsed, following predeformation in the high-stress range for homogeneous grain-boundary slips. The data from observations are also plotted in Fig. 2. The minimum time elapsed to observe the steady-state creep rate following predeformation was $\sim 1 \mathrm{ks}$, where the creep rate observed was about ten times that for a virgin specimen. When the elapsed time following predeformation increased, the creep rate decreased to about that for a virgin specimen. In situ STM observations during the tensile creep test were then carried out. The micrographs that were taken at elapsed times of $0.9 \mathrm{ks}, 10 \mathrm{ks}$, and $14 \mathrm{ks}$ after loading are in Figs. 3(a)-3(c). Although the specimen moved, the surface morphology could be observed. The dark spot in the figure can be used as a reference point. After the elapsed time of $10 \mathrm{ks}$, one secondary grain came out onto the specimen surface [the white spot in Fig. 3(b)]. After the elapsed time of $14 \mathrm{ks}$, the secondary grain sank into the specimen's surface [Fig. 3(c)].
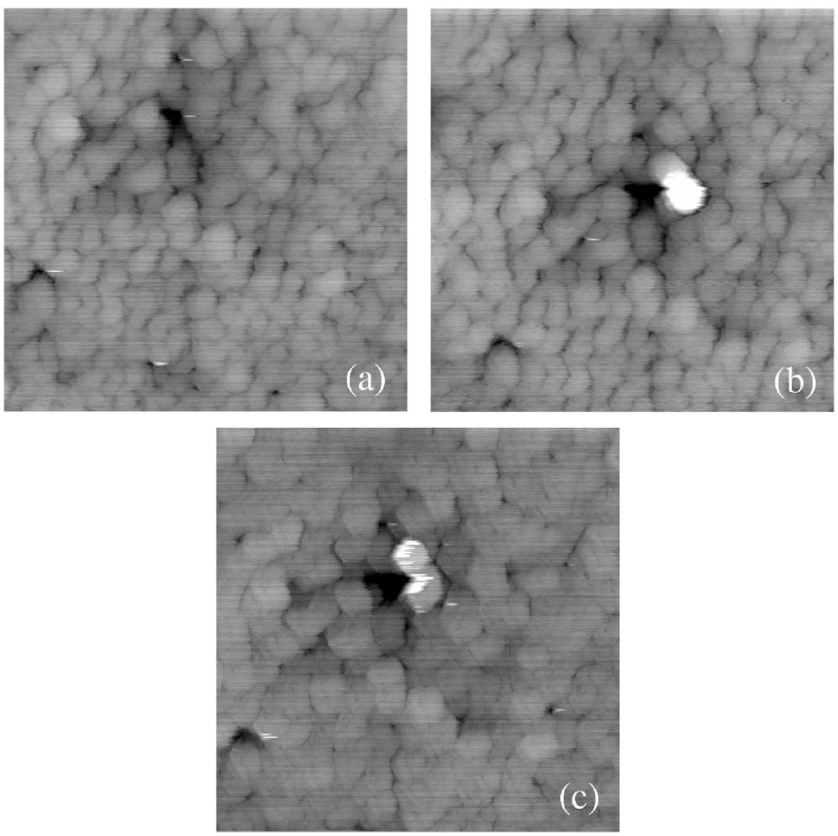

FIG. 3. In situ STM images of $n$-Au observed during tensile creep test at $150 \mathrm{MPa}$, where (a), (b), and (c) were observed at respective elapsed times of $0.9 \mathrm{ks}, 10 \mathrm{ks}$, and $14 \mathrm{ks}$ after loading. Total strain attained was $\sim 0.012 \%$. Scanning area is 1000 $\times 1000 \mathrm{~nm}^{2}$ and black-to-white height is $30 \mathrm{~nm}$.

Such secondary grain movements were frequently observed during creep deformation. It is noted that the apparent coarse-grained topography seen in Fig. 3(c) was due to an increased movement of the specimen but not due to grain growths. It is not shown here but the XRD measurements and STM observations conducted before and after creep tests indicated that the secondary grains with the size of $\sim 50 \mathrm{~nm}$ and the constituent primary grains with the mean size of $\sim 20 \mathrm{~nm}$ remained unchanged.

Figures 3(a)-3(c) demonstrate characteristic motion of secondary grains near the specimen surface. To obtain further insights into the motion of grains in specimens, additional XRD measurements were carried out on $n$-Au after creep deformation. Figure 4 has examples of XRD patterns for an $n$-Au specimen observed in the as-deposited state and after tensile creep deformation of 3\% at $140 \mathrm{MPa}$. (111) reflection was predominant for the $n$-Au specimens in the as-deposited

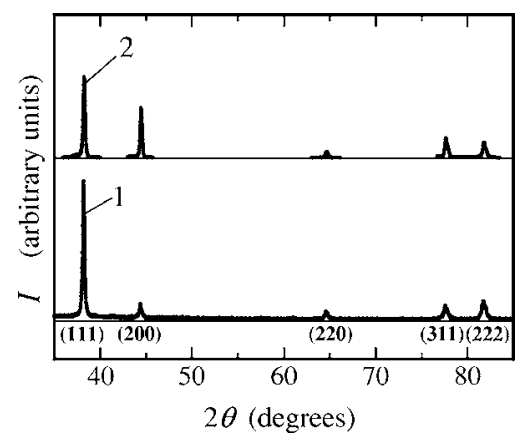

FIG. 4. XRD patterns observed for $n$-Au. 1: in as-deposited state and 2: after tensile creep deformation of $3 \%$ at $140 \mathrm{MPa}$. 


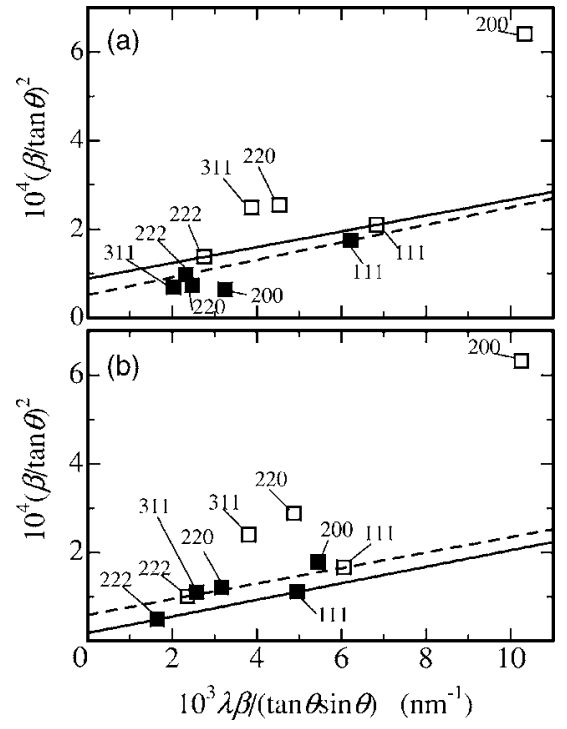

FIG. 5. (a) Wilson-Hall plots (Ref. 17) for XRD reflections observed for $n$-Au before (open symbols) and after tensile creep deformation of $1.5 \%$ under $150 \mathrm{MPa}$ (filled symbols). (b) Those before (open symbols) and after compressive creep deformation of $37 \%$ under $800 \mathrm{MPa}$ (filled symbols). $\beta$ is integrated width of reflection peak and $\lambda$ is wave length of $\mathrm{Cu} K \alpha$ radiation. In (a), mean grain size determined from (111) and (222) reflections, $d_{111}$, and local strain $\left\langle\varepsilon^{2}\right\rangle^{0.5}$, are $59 \mathrm{~nm}$ and $0.19 \%$ in as-deposited state and $53 \mathrm{~nm}$ and $0.14 \%$ after tensile creep deformation, respectively. In (b), $d_{111}$ and $\left\langle\varepsilon^{2}\right\rangle^{0.5}$ are $54 \mathrm{~nm}$ and $0.24 \%$ in as-deposited state and $51 \mathrm{~nm}$ and $0.13 \%$ after tensile creep deformation, respectively.

state. Deformation brought about a decrease in (111) reflection and an increase in (200) reflection. The mean grain size $d_{111}$, was estimated from (111) and (222) reflections by means of Wilson-Hall plots. ${ }^{17}$ Figure 5(a) has the WilsonHall plots of an $n$-Au specimen before and after tensile creep deformation of $1.5 \%$ under $150 \mathrm{MPa}$, and Fig. 5(b) has those before and after compressive creep deformation of $37 \%$ under $800 \mathrm{MPa}$. The XRD data in Figs. 4 and 5 indicate that the $n$-Au specimens in the as-deposited state have a strong $\langle 111\rangle$ texture with a $d_{111}$ of $\sim 50 \mathrm{~nm}$, and contain finer $\langle 100\rangle$ oriented grains with a very small volume fraction. Although the (111) reflection considerably decreased after creep deformation, $d_{111}$ and $\left\langle\varepsilon^{2}\right\rangle^{0.5}$ remained unchanged, and the data on the other XRD reflections was aligned with those for the (111) and (222) reflections on the Wilson-Hall plots. Figures 6(a)-6(c) plot $d_{111},\left\langle\varepsilon^{2}\right\rangle^{0.5}$, and lattice constant $a$, determined from the Wilson-Hall plots of $n$-Au specimens after tensile creep tests and those after compressive tests as a function of plastic strain $\varepsilon_{\mathrm{p}}$. With increasing $\varepsilon_{\mathrm{p}}, d_{111}$ remained unchanged, $\left\langle\varepsilon^{2}\right\rangle^{0.5}$ decreased, and $a$ increased toward the lattice constant for a bulk $\mathrm{Au}$ specimen.

Figure 7 shows the x-ray diffuse scattering pattern near the (111) reflection observed on an $n$-Au specimen in the as-deposited state and that after compressive creep deformation of $55 \%$, where the time for one measurement was $200 \mathrm{ks}$. The x-ray diffuse scattering pattern remained unchanged after strong creep deformation. Figures 8(a) and 8(b) plot the fractional intensity of the XRD (111) reflection

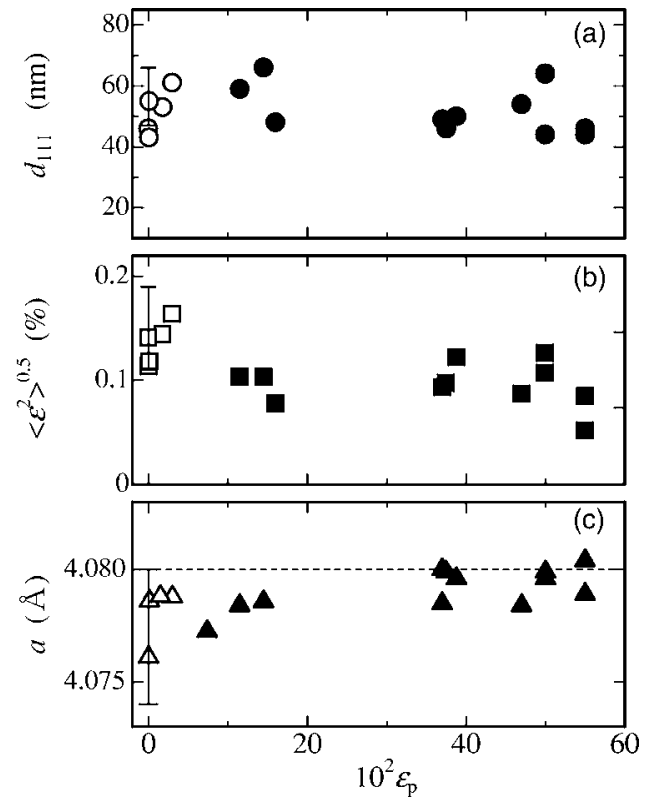

FIG. 6. (a) $d_{111}$, (b) $\left\langle\varepsilon^{2}\right\rangle^{0.5}$, and (c) lattice constant $a$, determined from Wilson-Hall plots for $n$-Au after tensile creep tests (open symbols). Those after compressive tests (filled symbols) are plotted against plastic strain $\varepsilon_{\mathrm{p}}$. The data observed before creep test are depicted at $\varepsilon_{\mathrm{p}}=0$ in the figures.

$I_{111} / I_{\text {total }}$, observed after tensile creep deformation and that after compressive creep deformation, where $I_{\text {total }}=I_{111}+I_{200}$ $+I_{220}$. The value of $I_{111} / I_{\text {total }}$ in the as-deposited state was higher than $90 \%$. The $I_{111} / I_{\text {total }}$ for tensile creep deformation rapidly decreased with increasing $\varepsilon_{\mathrm{p}}$. The $I_{111} / I_{\text {total }}$ for compressive creep deformation slowly decreased, then rapidly decreased. The deformation near the surface was constricted in the compressive creep test because the specimen surfaces were directly facing the instrument. The $228 \mu \mathrm{m}$ thick specimen after compressive creep deformation was chemically polished to remove these $57 \mu \mathrm{m}$ thick constricted surface layers and the $I_{111} / I_{\text {total }}$ was measured again. The results

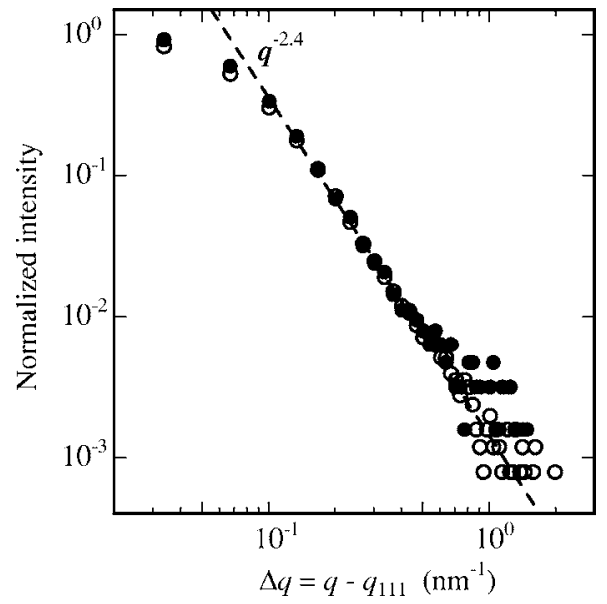

FIG. 7. X-ray diffuse scattering near (111) reflection observed for $n$-Au in as-deposited state (open symbols). That after compressive creep deformation of $55 \%$ under $600 \mathrm{MPa}$ is plotted by filled symbols. 


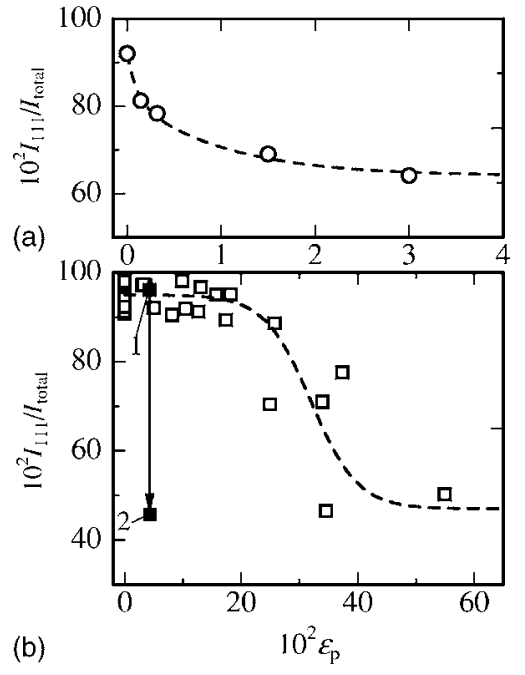

FIG. 8. (a) Fractional intensity of XRD (111) reflection $I_{111} / I_{\text {total }}$, observed for $n$-Au after tensile creep deformation under $140 \mathrm{MPa}$ and (b) that after compressive creep deformation under stresses between $300 \mathrm{MPa}$ and $1000 \mathrm{MPa}$, where $I_{\text {total }}=I_{111}+I_{200}$ $+I_{220}$ and $\varepsilon_{\mathrm{p}}$ is plastic creep strain. Dashed curves are provided for clarity. In (b), Data 2 was observed after chemical polishing of Specimen 1 (see text for details).

were plotted as the data 1 and 2 in Fig. 8(b), respectively, indicating that a rapid decrease in $I_{111} / I_{\text {total }}$ with increasing $\varepsilon_{\mathrm{p}}$ is also intrinsic for the compressive creep deformation. The slow decrease in $I_{111} / I_{\text {total }}$ observed for small plastic creep strains seen in Fig. 8(b) is due to the constraint surface layers during the compressive tests. As well as the results in Figs. 6 and 7, the change in $I_{111} / I_{\text {total }}$ in Fig. 8 suggests grain rotation in $n$-Au during creep deformation.

\section{DISCUSSION}

In Fig. 2, the creep rates in $n$-Au specimens were measured by means of tensile tests below $\sim 320 \mathrm{MPa}$ and compressive tests above $\sim 320 \mathrm{MPa}$, where both the data at $\sim 320 \mathrm{MPa}$ had good agreement. The dependence of the creep rate on stress in Fig. 2 reveals inflections at $\sim 150 \mathrm{MPa}$ and $\sim 500 \mathrm{MPa}$. The creep rate increases nearly linearly with increasing stress between $\sim 50$ and $\sim 150 \mathrm{MPa}$ (called Region I after this), increases steeply by $\sim 10^{6}$ times between $\sim 150$ and $\sim 500 \mathrm{MPa}$ (Region II), and then increases moderately above $\sim 500 \mathrm{MPa}$ (Region III). As has already been reported, ${ }^{9}$ with increasing stress, localized grain-boundary slips in Region I develop into homogeneous grain-boundary slips in Region III through transitional Region II. In the present work, we also found that the creep rate in Region III increased moderately with increasing stress, indicating that a steady deformation mode was attained for the homogeneous grain-boundary slips in Region III.

Figures 3(a)-3(c) demonstrate the characteristic motion of secondary grains near the specimen surface during creep tests, indicating that a secondary grain can move as a whole without reactions such as coalescence with neighboring grains. Further, although there was a strong decrease in the XRD (111) reflection with increasing creep deformation

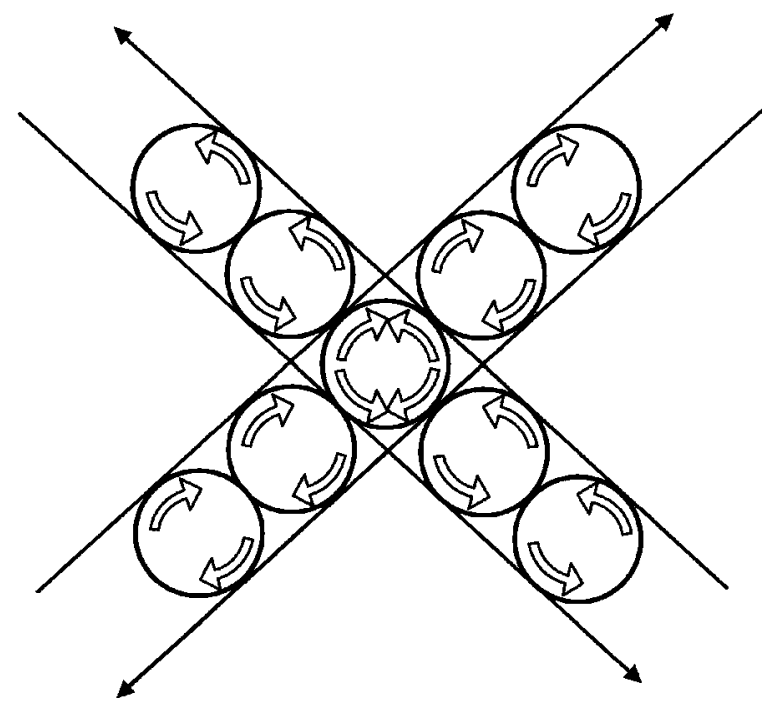

FIG. 9. Model of grain-boundary slips associated with grain rotations and anchoring due to crossing of slips.

[Figs. 8(a) and 8(b)], no changes in either the mean size of secondary grains [Fig. 6(a)] or the x-ray diffuse scattering pattern (Fig. 7) were found even after heavy creep deformations. Diffusion-mediated mechanisms cannot explain such characteristic motion in secondary grains and the change in the preferred orientation of the grains. These results indicate that the heterogeneous grain-boundary slips in $n$-Au are associated with the rotations of secondary grains as can be seen in Fig. 9. In Ref. 9, the creep deformation in Regions I and II was explained by the localized grain-boundary slips with the mean segment length of $200 \mathrm{~nm}$. In the STM observations after creep deformation (Fig. 7 in Ref. 9), the segments of the localized grain-boundary slips were not smooth but zigzag shaped with a fluctuation of $\sim 50 \mathrm{~nm}$. This feature also indicates that the grain-boundary slips are heterogeneously took place between the secondary grains accompanied with the rotation. Hasnaoui et al. reported the collective grain-boundary sliding of several grains from computer simulations done on the tensile deformation of $n-\mathrm{Ni}$ with a mean grain size of $5 \mathrm{~nm} .{ }^{18}$ Although they observed the rotation of several grains in collective grain-boundary sliding, the rotational angle was $\sim 2$ degrees after $2.2 \%$ deformation. They also observed grain refinement due to intragrain slip.

Sakai et al. ${ }^{9}$ and Tanimoto et al. ${ }^{15}$ found that the grainboundary anelastic process for $n$-Au could be thermally activated above $\sim 200 \mathrm{~K}$, where grain-boundary anelastic strain also increases greatly with increasing stress, e.g., the Young's modulus at $300 \mathrm{~K}$ measured in a tensile test under a few tens of megapascals is about half that with the vibrating-reed method under a few megapascals. These results indicate that grain-boundary anelastic strain increases more steeply than elastic strain with increasing stress. In other words, the atomic structures in the grain-boundary regions (surrounding the secondary grains) are considerably modified under increasing stress and recover with decreasing stress. During homogeneous grain-boundary slips, ultimate modifications of atomic structures in grain-boundary regions may be expected. Figure 2 shows whether such modifications in the 
grain-boundary regions is persistent or recoverable. As can be seen, the creep rate is about ten times larger just after predeformation but then has good agreement with that of a virgin specimen after a prolonged amount of time has elapsed. This indicates that modification in grain-boundary regions due to grain-boundary slips is recoverable after unloading, i.e., there are static and modified structures during slips in grain-boundary regions.

Shan et al., ${ }^{19}$ on the other hand, reported grain growth associated with grain rotations in $n$ - $\mathrm{Ni}$ with a mean grain size of $9.7 \mathrm{~nm}$ during tensile deformation, and Jin et al. ${ }^{20}$ reported it in $n$-Al with a mean grain size of $20 \mathrm{~nm}$ during an indentation test. Zhang et al. observed grain growth near indentations in $n-\mathrm{Cu}$ with a mean grain size of $35 \mathrm{~nm}$ and attributed decreased hardness with increased loading time (indentation creep) to the activation of a dislocation mechanism in grown grains. ${ }^{21}$ Haslam et al.'s computer simulations on the diffusion-mediated creep deformation of $n$-Pd with a mean grain size of $15 \mathrm{~nm}$ has suggested that grain growth is accompanied by grain rotation in order to decrease the interfacial energy. ${ }^{22}$ In contrast, no growth of secondary grains has been observed in $n$-Au specimens even after heavy deformation. As has already been discussed, Tanimoto et al. ${ }^{15}$ found the clustering of primary grains with a mean grain size of $\sim 20 \mathrm{~nm}$ to secondary grains with a mean size of $\sim 40 \mathrm{~nm}$ took place during deposition in $n$-Au specimens prepared with the GD method. The strong $\langle 111\rangle$ texture observed in $n$-Au specimens in the as-deposited state suggests that a rearrangement of the secondary grains took place to minimize the interfacial energy between the secondary grains. These results suggest that the grain-boundary slips, which are mediated by rotations of grains, may be the dominant deformation process when the grain size is in an appropriate range. That is, grain growth is expected in the smaller ranges and dislocation-mediated deformation is expected in the larger ranges.

To observe homogeneous deformation, the number density of grain-boundary slips should increase with increasing stress, whereas the dependence of the slip rate of an activated grain-boundary slip on stress should be moderate in Region III. The countering of torque where the slips cross (Fig. 9) is expected to play an important role when grain-boundary slips are developed, e.g., in homogeneous deformation in Region III. However, since such slip crossing is expected to play a minor role in heterogeneous deformation in Region I and in the early stage in Region II, the interfacial friction between neighboring rotating grains may govern the rate at which an activated grain-boundary slips as seen in Fig. 9. In order to clarify the mechanism in detail, further work is necessary.

\section{CONCLUSION}

Creep deformation tests were carried out on $n$-Au with a mean secondary-grain size of $\sim 50 \mathrm{~nm}$ at room temperature. It was observed that the secondary grains came up onto the specimen surfaces and sank into them in in situ STM observations done during the creep test. This indicates that secondary grains can move as a whole without reactions such as coalescence with neighboring grains, and diffusion-mediated mechanisms cannot explain such characteristic motion by secondary grains. Further, a large decrease in XRD (111) reflection and no changes in either the mean size of the secondary grains or the x-ray diffuse scattering pattern were observed after creep deformations. These results indicate that the grain-boundary slips were associated with rotations of the secondary grains. The characteristic dependence of creep deformation rate on stress found in virgin $n$-Au specimens was again observed in predeformed $n$-Au specimens, indicating that the modified grain-boundary regions due to grainboundary slips could be recovered after unloading, i.e., the grain-boundary regions had static and modified structures. However, further work to clarify details on grain-boundary structures is necessary.

\section{ACKNOWLEDGMENTS}

This work was partly supported by the 21 st Century COE (Center of Excellence) Program, the "Promotion of Creative Interdisciplinary Materials Science for Novel Functions," and a Grant-in-Aid for Scientific Research from the Ministry of Education, Culture, Sports, Science and Technology, Japan. The authors are greatly indebted to E. Kita for his kind help in preparing the specimens.
${ }^{1}$ E. O. Hall, Proc. Phys. Soc. London, Sect. B 64, 747 (1951).

${ }^{2}$ N. J. Petch, J. Iron Steel Inst., London 174, 25 (1953).

${ }^{3}$ T. G. Nieh and J. Wadsworth, Scr. Metall. Mater. 25, 955 (1991).

${ }^{4}$ R. A. Masumura, P. M. Hazzledine, and C. S. Pande, Acta Mater. 46, 4527 (1998).

${ }^{5}$ S. Takeuchi, Scr. Mater. 44, 1483 (2001).

${ }^{6}$ G. J. Fan, H. Choo, P. K. Liaw, and E. J. Lavernia, Mater. Sci. Eng., A 409, 243 (2005).

${ }^{7}$ R. L. Coble, J. Appl. Phys. 34, 1679 (1963).

${ }^{8}$ M. F. Ashby and R. A. Verrall, Acta Metall. 21, 149 (1973).

${ }^{9}$ S. Sakai, H. Tanimoto, E. Kita, and M. Mizubayashi, Phys. Rev. B 66, 214106 (2002).
${ }^{10}$ H. Tanimoto, T. Yamada, N. Yagi, and H. Mizubayashi, Proc. of Int. Conf. on Adv. Tech. in Experimental Mechanics 2003, edited by Y. Akiniwa, H. Kimura, and K. Tanaka (Japan Soc. of Mech. Eng., Tokyo, 2004), OS06W0399.

${ }^{11}$ B. Cai, Q. P. Kong, L. Lu, and K. Lu, Mater. Sci. Eng., A 286, 188 (2000).

${ }^{12}$ B. Cai, Q. P. Kong, P. Cui, L. Lu, and K. Lu, Scr. Mater. 45, 1407 (2001).

${ }^{13}$ N. Wang, Z. Wang, K. T. Aust, and U. Erb, Mater. Sci. Eng., A 237, 150 (1997)

${ }^{14}$ W. M. Yin, S. H. Whang, R. Mirshams, and C. H. Xiao, Mater. Sci. Eng., A 301, 18 (2001).

${ }^{15}$ H. Tanimoto, S. Sakai, E. Kita, and H. Mizubayashi, Mater. 
Trans. 44, 94 (2003).

${ }^{16}$ S. Sakai, H. Tanimoto, and H. Mizubayashi, Acta Mater. 47, 211 (1999).

${ }^{17}$ H. P. Klug and L. E. Alexander, X-ray Diffraction Procedures for Polycrystalline and Amorphous Materials, 2nd ed. (Wiley, New York, 1974), pp. 661-665.

${ }^{18}$ A. Hasnaoui, H. Van Swygenhoven, and P. M. Derlet, Phys. Rev. B 66, 184112 (2002).
${ }^{19}$ Z. Shan, E. A. Stach, J. M. K. Wiezorek, J. A. Knapp, D. M. Follstaedt, and S. X. Mao, Science 305, 654 (2004).

${ }^{20}$ M. Jin, A. M. Minor, E. A. Stach, and J. W. Morris, Jr., Acta Mater. 52, 5381 (2004).

${ }^{21}$ K. Zhang, J. R. Weertman, and J. A. Eastman, Appl. Phys. Lett. 85, 5197 (2004).

${ }^{22}$ A. J. Haslam, V. Yamakov, D. Moldovan, D. Wolf, S. R. Phillpot, and H. Gleiter, Acta Mater. 52, 1971 (2004). 